\title{
Correction: Association Between State Indoor Tanning Legislation and Google Search Trends Data in the United States From 2006 to 2019: Time-Series Analysis
}

Carolyn Heckman ${ }^{1}$, PhD; Yong Lin ${ }^{1}, \mathrm{PhD}$; Mary Riley ${ }^{2}$, MPH; Yaqun Wang ${ }^{1}, \mathrm{PhD}$; Trishnee Bhurosy ${ }^{1}, \mathrm{PhD}$; Anna Mitarotondo ${ }^{1}$, BA; Baichen $\mathrm{Xu}^{1}$, MS; Jerod Stapleton ${ }^{3}, \mathrm{PhD}$

${ }^{1}$ Rutgers Cancer Institute of New Jersey, New Brunswick, NJ, United States

${ }^{2}$ Medtronic, Denver, CO, United States

${ }^{3}$ University of Kentucky, Lexington, KY, United States

Corresponding Author:

Carolyn Heckman, PhD

Rutgers Cancer Institute of New Jersey

195 Little Albany St

New Brunswick, NJ, 08901

United States

Phone: 17322358830

Email: ch842@rutgers.edu

Related Article:

Correction of: https://derma.jmir.org/2021/1/e26707

(JMIR Dermatol 2021;4(1):e29516) doi: 10.2196/29516

In "Association Between State Indoor Tanning Legislation and Google Search Trends Data in the United States From 2006 to 2019: Time-Series Analysis" (JMIR Dermatol 2021;4(1):e26707) the authors noted two errors.

Due to a system error, the name of one author, Trishnee Bhurosy, was replaced with the name of another author on the paper, Jerod Stapleton. In the originally published paper, the order of authors was listed as follows:

Carolyn Heckman; Yong Lin; Mary Riley; Yaqun Wang; Jerod Stapleton; Anna Mitarotondo; Baichen $\mathrm{Xu}$; Jerod Stapleton

This has been corrected to:
Carolyn Heckman; Yong Lin; Mary Riley; Yaqun Wang; Trishnee Bhurosy; Anna Mitarotondo; Baichen

$\mathrm{Xu}$; Jerod Stapleton

In the originally published paper, the ORCID of author Trishnee Bhurosy was incorrectly published as follows:

Trishnee Bhurosy: 0000-0002-8501-1483

This has been corrected to:

Trishnee Bhurosy: 0000-0003-2603-2839

The correction will appear in the online version of the paper on the JMIR Publications website on April 14, 2021, together with the publication of this correction notice. Because this was made after submission to PubMed, PubMed Central, and other full-text repositories, the corrected article has also been resubmitted to those repositories.

This is a non-peer-reviewed article. Submitted 09.04.21; accepted 09.04.21; published 14.04.21.

Please cite as:

Heckman C, Lin Y, Riley M, Wang Y, Bhurosy T, Mitarotondo A, Xu B, Stapleton J

Correction: Association Between State Indoor Tanning Legislation and Google Search Trends Data in the United States From 2006 to 2019: Time-Series Analysis

JMIR Dermatol 2021;4(1):e29516

URL: https://derma.jmir.org/2021/1/e29516

doi: $\underline{10.2196 / 29516}$

PMID: 
(C) Carolyn Heckman, Yong Lin, Mary Riley, Yaqun Wang, Trishnee Bhurosy, Anna Mitarotondo, Baichen Xu, Jerod Stapleton. Originally published in JMIR Dermatology (http://derma.jmir.org), 14.04.2021. This is an open-access article distributed under the terms of the Creative Commons Attribution License (https://creativecommons.org/licenses/by/4.0/), which permits unrestricted use, distribution, and reproduction in any medium, provided the original work, first published in JMIR Dermatology Research, is properly cited. The complete bibliographic information, a link to the original publication on http://derma.jmir.org, as well as this copyright and license information must be included. 